\title{
THE ROLE OF PELVIC FLOOR IMPAIRMENT AS A CONTRIBUTORY FACTOR TO URINARY INCONTINENCE IN PATIENTS WITH BLADDER INSTABILITY
}

\author{
A. PISCHEDDA, F. PIROZZI FARINA, A. MATTANA \\ M. DERIU, G. SOLINAS 1, E. BERCOVICH \\ Institute of Urology - University of Sassari \\ 1 Institute of Hygiene and P.H. - University of Sassari
}

Keywords:

Unstable bladder - Urinary incontinence - Pelvic floor impairment - electromyography - oxybutynin.

\begin{abstract}
Unstable bladder symptomatology often includes different types of urinary incontinence. We assessed the possible correlation between urinary incontinence associated with an unstable bladder and pelvic floor activity. In addition, we assessed when oxybutynin administration bas favourable effects on urinary incontinence associated with an unstable bladder. Sixty female patients affected by an unstable bladder, consecutively enrolled in the study, were evaluated by means of urodynamics and diagnostic electromyography. Urinary incontinence, when present, was characterized. Possible correlation between types of urinary incontinence and types of pelvic floor dysfunction was investigated. Oxybutynin $5 \mathrm{mg} . x 3 /$ day was administered per os. Drug activity was evaluated in terms of outcome for the different types of urinary incontinence. A prevailing reduction in maximal muscle contraction and endurance in the patients affected by stress and mixed urinary incontinence was found. 42\% of the patients affected by urge incontinence showed a decrease in endurance, and 52\% showed overall good functioning of their pelvic floor. Administration of oxybutynin only improved urinary incontinence in those patients affected by urge incontinence who did not have pelvic floor dysfunction (exact Fisher's test, $p<0.001$ ).
\end{abstract}




\section{INTRODUCTION}

Detrusor overactivity is a lower urinary tract dysfunction characterized by involuntary, spontaneous or provoked, detrusor contractions during bladder filling or while the subject tries to inhibit micturition. The International Continence Society (ICS) has proposed a classification in which involuntary bladder contractions associated with known neurological disease come within the category of detrusor hyperreflexia, while the term unstable detrusor, or bladder instability, is applied to such activities that occur in a patient with no known neurological disease (1). Detrusor hyperactivity, regardless of its origin, generally manifests through a symptoms complex commonly known as Urge Syndrome (US) (2). This syndrome includes frequency, nocturia, and urgency which may be associated with to urge incontinence (3). The patients may refer enuresis or a history of enuresis during their childhood. In females with US, stress incontinence and/or incontinence during sexual intercourse may be present (4-6).

Several etiological hypotheses have been put forward to explain bladder instability: congenital disease $(7,8)$, aging (9), intravesical obstruction (10-12), urethral instability $(13,14)$, urethral incompetence $(10,15)$, and psychosomatic origin $(16,17)$. However, at present, bladder instability is considered an idiopathic disease (2). Consequently, therapy aims to fight symptoms and discomfort $(2,3)$. Medication, electrostimulation and behavioural therapy are commonly used. Anticholinergics
$(18,20)$, myotropic anticholinergics (21-26), myorelaxants (27,29), calcium antagonists (30-32), beta-adrenergic agonists (33), and tricyclic antidepressants (34-35) are the drugs mainly employed. The rationale for the use of these drugs is to inhibit bladder overactivity and/or to rehabilitate cholinergic and adrenergic neuromodulation, although Wagg et al (37) report a lack of correlation between symptomatic improvement and urodynamic findings.

Electrostimulation (employing a vaginal or an anal probe) is currently used in order to improve sphincteral tonus and its control, to obtain improved continence. Electrostimulation would be able to reduce detrusor hyperactivity (38).

Behavioural treatments, such as biofeedback (39) and bladder drill $(17,40)$, aim for better cortical control of pelvic musculature and micturitional reflex.

\section{Aims}

The purpose of our trial was to better define indications for pelvic floor rehabilitation as a treatment for bladder instability associated with urinary incontinence. Pelvic floor performance in female subjects affected by detrusor instability was assessed, and urinary incontinence, when present, was characterized. Possible correlations between urinary incontinence and pelvic floor impairment, and between the type of incontinence and pelvic floor impairment, were investigated. All the patients were administered oxybutynin, an anticholinergic and myorelaxant medication, in order to evaluate the role of detrusor 
overactivity in determining urinary incontinence. The response to this medication in terms of incontinence changes was evaluated during the follow-up. Finally, we assessed whether any incontinence changes due to medical therapy could be correlated either with the type of incontinence, or with pelvic floor functionality.

\section{MATERIALS AND METHODS}

All the female patients with urge syndrome under study were enrolled consecutively in the trial between January 1996 and June 1999.

\section{Enrolment criteria and case}

histories: All the patients affected by urge syndrome were taken into consideration beforehand. A detailed clinical history was obtained and a uro-gynaecological examination, urine analysis, urine culture, urinary cytology, and a urinary apparatus ultrasound scan were performed. Cystoscopy and/or cystograms were employed when considered necessary. This first step made it possible to identify 111 patients affected by urgency with a suspected motor cause. A voiding chart was completed by these patients (44) and cystomanometry (CMG) and urethral pressure profile (PPU) were performed. CMG characterized 13 patients with sensitive urgency (43), and 98 patients with detrusor overactivity. Neurological assessment identified 31 out of 98 cases of detrusor hyperreflexia. The remaining 67 patients were characterized as affected by bladder instability. Four patients with contraindications to the use of oxybutynin (1 oesophagitis, 1 ulcerative colitis, 1 hyperthyroidism, and 1 glaucoma) and 3 patients who refused to undergo an electromyographic assessment, were excluded.

Sixty women aged from 21-68 yrs. (average: 46, s.d. 11.1) with bladder instability were consecutively enrolled. All the patients completed the pre-treatment study with a cardiology check-up, and a renal and liver function work-up, in order to exclude contraindications to oxybutynin. Pregnancy was ruled out in the fertile patients. No further drop-outs occurred in this cohort.

Voiding chart: this was evaluated before treatment and at day 30. A summary of voiding chart results, together with anamnesis and clinical information, is shown in the pre- and post-treatment table.

Urodynamic study: First, Urogyn 2000 MMS (Medical Measurement System, Wheaton, IL), and then a Duet Dantec (Dantec Medical, Inc. Mahwah, NJ) machine, with 8 Fr. catheters with Dantec 9022k0626 (bladder) and 9022k0606 (rectal) tip transducer catheters, were employed.

Filling cystometry was performed with the patient in a sitting position and with a filling rate of $30 \mathrm{ml} / \mathrm{min}$ (1). Intravesical pressure (Pves), intraabdominal pressure (Pabd), and detrusor pressure (Pdet) were recorded.

Occult detrusor instability was investigated by means of provocative manoeuvres such as: increase of filling rate, coughing, infusion in a standing position (37). 
The following parameters were also recorded: Pdet during non-inhibited contractions, bladder volume at the moment of involuntary detrusor contraction onset, maximum cystometric capacity and compliance. Bladder instability was diagnosed if phasic involuntary contractions during the filling phase were present, and also if at Pdet lower than $15 \mathrm{~cm}$. $\mathrm{H}_{2} \mathrm{O}$ (46). For a better definition of stress incontinence when associated with bladder instability, urethral pressure profile (UPP) was performed (47). This study was carried out with the patient in supine position after $100 \mathrm{ml}$ of saline had been infused. 8 Fr. Dantec 9022k0626 tip transducer catheters were used with the sensor positioned laterally (48). First a resting UPP (RUPP) was obtained, thereby eliciting provocative stimuli such as coughing and the Valsalva manoeuvre from the patients (SUPP) (49) for dynamic measurements. The catheter was retracted at a constant rate of $2 \mathrm{~mm} / \mathrm{sec}$. Maximum urethral pressure, maximal urethral closure pressure and urethral functional length, with and without stimulation, were measured. The same urodynamic trial was performed at day 30 of therapy.

\section{Kinesiological electromyogra-} phy (EMGK): This investigation was carried out on levator ani and rectum abdominal muscles by means of dual channel machines. First a Gymna MYO 220 (Gymna-Pasweg, Bilzen), and then a SygMax Plus SN 98102 (Sygma Byo Medical-La Garde, France) device were employed. Disposable superficial patch electrodes were applied.

The test was performed in a soundproof room and in a thermoconditioned environment. The patients were fully informed about the significance of the examination in progress, and their active participation was requested. Before starting the test the physician applied the electrodes to his own forearm muscles and demonstrated the dynamics of the test on monitor screen (50). Then the patients were placed in slight lithotomic position, and the electrodes were applied in the perianal zone at 10 and 2 o'clock, and on the median line $3-5 \mathrm{~cm}$ below the umbilicus.

EMGK was performed as follows: first the patients were instructed to contract the anal sphincter in order to withhold micturition, and at the same time, to follow the graph line on the monitor. This coaching helped the patients to identify the muscles involved in the test and to practise the session.

Patients repeated ten pelvic contractions of 6-second duration, with a 12-second pause between each contraction. Phasic component and endurance were thereby evaluated. The dual channel enabled determination of any abdomino-perineal antagonist contractions or "inversion of command" $(41,51)$.

\section{Pharmacological Treatment:} oxybutynin chlorhydrate (Ditropan) was given per os. at a dosage of 5 $\mathrm{mg}$. three times daily for a period of 90 days. First follow-up was scheduled at day 30 . 
Data processing: Initially age and clinical information from the cohort of 60 patients was sequentially recorded on an Excel table according to enrolment time. Micturition frequency, any presence of nocturia and micturition/night, and the presence/absence of urgency were reported. The type of incontinence, when present, was classified as urge, stress or mixed urinary incontinence. Finally, the results of EMGK in terms of maximal contraction, endurance and the presence/absence of abdomino-perineal dyssynergia were reported. The data obtained were further processed. Independence among qualitative variables was evaluated by Fisher's test. Variables correlation was studied by means of Sperman's factor. The Windows Statistical Package for the Social Sciences, version 6.1.3 (SPSS) was employed for descriptive analysis.

\section{RESULTS}

The results are reported as numeric values and percentages and in statistical tables. None of the 60 patients reported adverse effects related to the oxybutynin medication requiring dose reduction or drug withdrawal.

Group 1: 6 patients (10\%) without incontinence aged 21-61 yrs. (mean 38 yrs).

Pelvic floor assessment showed:

- 2 patients (33\%) without dysfunction.

- 2 patients (33\%) with slight abdominal and perineal musculature synergic contractions (APMSC) but with normal pelvic floor function.
- 2 patients (33\%) without APSMC: one with maximal contraction impairment, and the other with maximal contraction and endurance impairment.

Mean voiding frequency was 10/24 hrs. Nocturia was present in 4 patients. All the patients referred urgency. After 30 days of administration of oxybutynin, voiding frequency decreased to $7 / 24$ hrs and 5 patients (83\%) referred a normal micturition pattern. Urgency improved in 2 patients (33\%) and decrease of nocturia improved in 2 out of 4 initially affected patients (50\%).

Group 2: 19 patients (32\%) with urge incontinence aged 26-59 yrs. (average 42 yrs.).

Pelvic floor assessment showed:

- 5 patients $(26 \%)$ with no dysfunction.

- 5 patients (26\%) with slight APSMC but normal pelvic floor contractility.

- 6 patients (32\%) with APSMC and endurance reduction.

- 1 patient (5\%) with APSMC and low maximal contraction.

- 2 patients (10\%) without APSMC: one with both maximal contraction and endurance impairment, and the other with only endurance reduction.

Mean voiding frequency in this group was 10/24 hrs. Urgency was detected in 18 patients (95\%), and nocturia in 15 patients (79\%). After 30 days of administration of oxybutynin the frequency decreased to $7 / 24 \mathrm{hrs}$. and 5 patients (26\%) referred normal voiding. Urgency improved in 8 (44\%) out of 18 patients; nocturia improved in $7(47 \%)$, and was resolved in 4 
(27\%) out of 15 patients. Ten patients (53\%) became continent or had marked improvement of continence.

Group 3: 20 patients (33\%) with stress incontinence aged 26-64 yrs. (mean 51 yrs.).

In all the patients pelvic floor dysfunction was identified:

- 11 patients (55\%) with dyssynergic contractions: 6 (30\%) with maximal contraction impairment, 5 (25\%) with both maximal contractions and endurance impairment. In one patient an inversion of the command was present.

- 9 patients (45\%) without APSMC: 3 (15\%) with endurance impairment, and $6(30 \%)$ with both maximal contractions and endurance impairment.

Mean voiding frequency was 10/ 24 hrs. Urgency was referred in $17 \mathrm{pa}$ tients (85\%), nocturia in 17 (85\%). After 30 days of therapy the voiding number decreased to $8 / 24 \mathrm{hrs}$. and normal micturition was achieved by 7 patients (35\%). Urgency improved in 6 (35\%) out of 17 patients and nocturia decreased in 8 (47\%) out of $17 \mathrm{pa}$ tients, and 3 patients resolved this symptom (18\%). Therapy in this group was ineffective with regard to incontinence.

Group 4: 15 patients (25\%) aged 27-68 yrs. (mean 49 yrs.) with mixed incontinence.

All the patients presented pelvic floor dysfunction:

- 10 patients (67\%) presented APSMC: 1 (7\%) with decreased maximal contraction and 9 (60\%) with both maximal contraction and endurance decrease.

- 5 patients (33\%) without APSMC: 1 (7\%) with maximal contraction decrease, and 4 (27\%) with both maximal contraction and endurance decrease.

Mean voiding frequency was 12/ 24 hrs., urgency was present in 14 patients (93\%), and nocturia was referred by 13 patients (87\%). At day 30 of therapy voiding frequency decreased to $10 / 24$ hrs. and resulted normal in 3 patients (20\%).

Urgency improved in 3 (21\%) out of 14 patients, nocturia improved in 5 (38\%) out of 13 patients, and was resolved in 5 patients (38\%). In one case mixed incontinence changed to stress incontinence. In all other cases incontinence remained unmodified.

Overall, 46 pts (77\%) showed pelvic floor impairment; 44 out of these (96\%) showed associated urinary incontinence $(r$ of Spearman $=0.34$ : $\mathrm{p}<0.05)$. The remaining $14 \mathrm{pts}$, $(23 \%$ of the total) did not show any pelvic floor impairment but urinary incontinence was present in 10 pts (71\%) from this group (Tab. I).

Table II shows sample distribution with regard to presence and type of urinary incontinence, and the efficacy of oxybutynin on urinary incontinence. An improvement in urinary incontinence following medical treatment was only found in the patients affected by urge incontinence without pelvic floor impairment (exact Fisher's test $\mathrm{p}<$ 0.001). This kind of association between urinary incontinence and pelvic floor dysfunction led us to analyse the serie in relation to the type of urinary incontinence and pelvic floor impairment (Tab. III - Fig. 1). 
Tab I - Sample distribution with urinary incontinence and pelvic floor impairment.

\begin{tabular}{|c|c|c|c|c|}
\hline & & \multicolumn{3}{|c|}{ urinary incontinence } \\
\hline $\begin{array}{c}\text { Pelvic floor } \\
\text { impairment }\end{array}$ & $\begin{array}{c}\text { No. } \\
\text { patients }\end{array}$ & $\%$ & No. Patients & $\%$ \\
\hline YES & 46 & 76,6 & 44 & 95,7 \\
\hline NO & 14 & 23,4 & 10 & 71,4 \\
\hline$(r=0.34 ; p<0,05)$ & & & & \\
\hline
\end{tabular}

Tab. II - Type of urinary incontinence in patients affected by bladder instability and oxybutynin outcome on urinary incontinence related to the presence or absence of pelvic floor dysfunctions.

\begin{tabular}{|c|c|c|c|c|c|c|}
\hline \multirow[b]{2}{*}{ Urinary incontinen } & & \multicolumn{2}{|c|}{ Pre-treatment } & \multicolumn{2}{|c|}{ Post-treatment } & \multirow{2}{*}{$p$ value } \\
\hline & nce & N & $\%$ & $N$ & $\%$ & \\
\hline no urinary incontine & ence & 6 & 10 & - & - & - \\
\hline & pelvic floor impairment & 9 & 47,4 & 0 & - & - \\
\hline \multirow[t]{2}{*}{ Urge } & & & & & & \\
\hline & no pelvic floor impairment: & 10 & 52,6 & 10 & 100 & $<0,001$ \\
\hline Stress & & 20 & & 0 & - & \\
\hline Mixed & & 15 & & 0 & - & \\
\hline
\end{tabular}

Fig. I - Sample percentage distribution related to type of urinary incontinence and pelvic floor dysfunction.
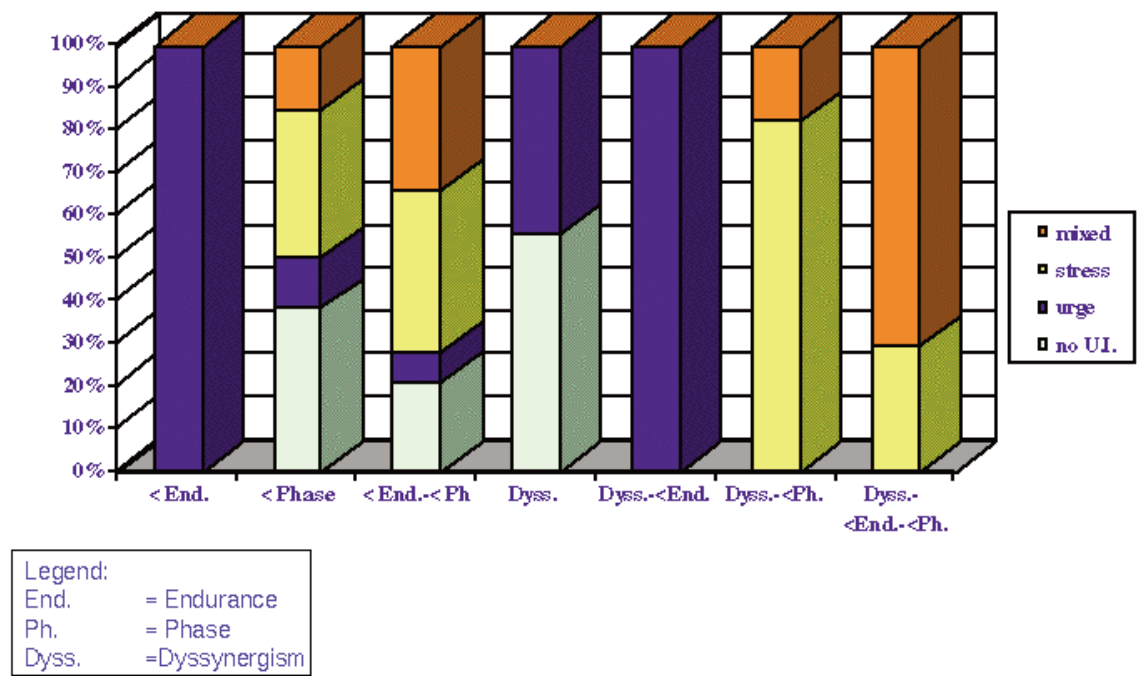
Tab. III - Sixty patients distribution related to type of urinary incontinence and pelvic floor dysfunction.

\begin{tabular}{|c|c|c|c|c|c|}
\hline Type of uinary Incominence & - Enduances & $\therefore$ Prase & $\begin{array}{c}\text { - enaugance } \\
\text { and } \\
\text { x Pnose }\end{array}$ & Dyssyneglsm & $\begin{array}{l}\text { Dyssynemis m } \\
\text { and } \approx \text { Enducand }\end{array}$ \\
\hline absence & 0 & T & T & 2 & 0 \\
\hline urge incontinence & 1 & 1 & 1 & 5 & 6 \\
\hline stress incontinence & 0 & 3 & 6 & 0 & 0 \\
\hline mixed incontinence & 0 & 1 & 4 & 0 & 0 \\
\hline Totel & 1 & $\overline{6}$ & 72 & 7 & $\overline{6}$ \\
\hline Type of uinary incomlinence & $\begin{array}{l}\text { Dyssynengls m } \\
\text { and }=\text { Prose }\end{array}$ & \multicolumn{2}{|c|}{$\begin{array}{l}\text { Drssynenglsm, } \\
\text { x Enducance } \\
\text { and = Pnsse }\end{array}$} & $\begin{array}{c}\text { Adsence of pewk } \\
1 \text { bor lmpalment }\end{array}$ & Tolal \\
\hline absence & 0 & \multicolumn{2}{|r|}{0} & 2 & $\overline{\mathrm{B}}$ \\
\hline urge incontinence & 0 & \multicolumn{2}{|r|}{0} & 5 & 19 \\
\hline stress incontinence & 6 & \multicolumn{2}{|r|}{5} & 0 & 20 \\
\hline mixed incontinence & 1 & \multicolumn{2}{|r|}{9} & 0 & 15 \\
\hline Totel & 7 & \multicolumn{2}{|r|}{74} & 7 & 60 \\
\hline
\end{tabular}

\section{DISCUSSION \& CONCLUSIONS}

Several therapeutic modalities are currently employed as single tools or in combination in accordance with well-established procedures or on the basis of personal experience. The most common approaches are anticholinergic musculotropic drugs acting on the detrusor, and the rehabilitation of the pelvic floor. The response to therapy in terms of symptoms such as urgency and/or incontinence is usually the main criterion of efficacy. The urge syndrome and the frequent presence of incontinence (urge, stress or mixed urge/stress) are the main factors which lead to rehabilitation for this disturbance.

It is worth mentioning that pelvic floor dysfunction could play an important role in the onset of stress incontinence. There is evidence in current lit- erature that the association between bladder instability, urge incontinence, and anatomic stress incontinence is quite common (52).

Resnick and Yalla state that pelvic floor weakness may cause urethral insufficiency, which may lead to stress incontinence and consequential detrusor overactivity (53).

Based on this assumption, electrostimulation $(54,55)$ and/or biofeedback $(38,39,56)$ are employed for incontinence associated with bladder instability.

However, it seems important to find a prior-to-therapy rationale for the employment of these pelvic floor rehabilitation techniques, which may enable a selection of suitable cases of bladder instability. However, the role of the pelvic floor should not be overestimated. In fact urinary incontinence caused by bladder instability in females with 
no cause of urinary incontinence may be present. A case of «idiopathic detrusor instability", which causes incontinence in bladder instability, was reported by Award (57). Patients affected by this condition would present urge incontinence with normal pelvic floor activity and could benefit from anticholinergic drugs such as oxybutynin.

Pubococcygeal EMGK, an expression of levator ani activity, was chosen as a preliminary investigation. EMGK registers the potential difference of muscular contraction and converts it into quantified sensorial information. EMGK is able to give information about barely conscious biological processes. EMGK screening could be useful in order to evaluate overall pelvic floor activity, aimed at better a scheduling of physio-kinesiologic treatment. Patch electrodes, rather than vaginal or rectal probes, were used for improved patient compliance, and have a similar diagnostic reliability. Electromyographic or manometric endovesical methods could be successfully employed in therapy. The administration of oxybutynin enabled evaluation of when this medication was effective for urinary incontinence, and, in particular, which type of urinary incontinence and which pelvic floor situation, responded best. Our study found that the administration of oxybutynin has a better outcome with regard to the frequency/urgency syndrome than to urinary incontinence. Severe pelvic floor dysfunction was absent when oxybutynin acted on urinary incontinence. In particular, oxybutynin only improved urge incontinence without pelvic floor impairment. Mixed urinary incontinence changed to stress incontinence in one patient. Pelvic floor assessment showed that urge incontinence was not always associated with pelvic floor dysfunction; however, when present it was often an expression of decreased endurance. On the other hand, stress or mixed urinary incontinence, was always associated with pelvic floor impairment. In these patients we more frequently found an associated decrease in maximal muscular contraction and endurance. In the patients affected only by stress urinary incontinence, we found a more important impairment of maximal contraction.

Based on EMGK results four types of patients were identified: 1) patients with normal pelvic floor activity; 2) patients with slight abdomino-perineal co-synergism but normal maximal contraction ability and endurance 3) patients with abdomino-perineal dyssynergia and a variable degree of maximal contractility impairment and endurance 4) non-dyssynergic patients with a variable degree of maximal contraction inadequacy and endurance. Thus two types of pelvic floor dysfunctions are present in these patients: intrinsic muscular deficiency and dyssynergia.

We therefore believe that intrinsic muscular deficiency may be the pathogenetic factor of stress incontinence, while dyssynergia decreases the ability of inhibition of detrusor contractions, decreasing pelvic floor performance.

This study shows that, when urinary incontinence is associated with bladder instability, the type of incon- 
tinence and pelvic floor contractility must be assessed. EMKG seems suitable for pre-therapy screening of these patients due to its ability to assess overall pelvic floor activity. Indeed, by employing this technique, we found that only half of the patients affected by urge incontinence, and some without urinary incontinence, had a normal pelvic floor function. Pelvic floor impairment was related to urinary incontinence in all the remaining cases. In particular, a reduction in endurance characterized the remaining $50 \%$ of the urgency incontinence cases; a decrease in maximal muscular contraction, whether associated or not, to a decrease in endurance was present in stress and mixed urinary incontinence. A treatment of five $\mathrm{mg} \times \mathrm{x}$ /day of oxybutynin showed that this drug can act only on urge incontinence without pelvic floor dysfunction. In conclusion, we think that pelvic floor assessment should be considered as a basic test in evaluating patients with bladder instability.

Dr. Antonella Pischedda

Istituto di Clinica Urologica

Università di Sassari

V.le Italia, 11

07100 Sassari

\section{REFERENCES}

1 - ABRAMS P.H., BLAIVAS J.G., STANTON S.L., ANDERSON J.T. :

The standardisation of terminology of lower urinary tract function.

Br J Obstet Gynaecol 1990; Suppl 6:1.

2 - STEPHENSON T.P., MUNDY A.R. :

The urge syndrome.

In Mundy AR, Stephenson TP, Wein AJ (eds): Urodynamics: principles, practice and application $2^{\text {nd }}$ ed. Churchill Livingstone, 1994, New York; 19:299.

3 - MARCK S.D., WEBSTER G.D. :

Detrusor Hyperactivity.

In Raz S (ed): Female Urology 2nd ed. 1996, Philadelphia, Saunders Co; 20:231.

4 - CANTON T.G., BATES C.B. :

A comparative study of symptoms and objective urodynamic finding in 214

incontinent women.

Br J Obstet Gynecol 1980; 87:889.

5 - CARDOZO L., STANTON S.L. :

Genuine stress incontinence and detrusor instability: A clinical and urodynamic review of 200 cases.

Br J Obstet Gynecol 1980; 87(3):184.

6 - DEL CARRO U., RIVA D., COMI G.C., LOCATElli T., MAGNANI G., LEVATI N., VIGANO R., SAMBRUNI I., CANAL N. :

Neurophysiological evaluation in detrusor instability.

Neurourol Urodyn 1993; 12(5):455. 
7 - WHITESIDE C.G., ARNOLD E.P. :

Persistent primary enuresis: A urodynamic assessment.

Br Med J 1975; 1:364.

8 - TORRENS M.J., COLLINS C.D. :

The urodynamic assessment of adult enuresis.

Br J Urol 1975; 47:433.

9 - GRIFFITHS D.N., MCCRACKEN P.N., MOORE K. :

Location of cerebrolesion responsible for geriatric urge incontinence.

ICS Abstract, Proceedings of the International Continence Society, Neurourol

Urodyn 1992; 11:422.

10 - ABRAMS P. :

Detrusor instability and bladder outlet obstruction.

Neurourol Urodyn 1985; 4:317.

11 - CUCCHI A. :

Detrusor instability and bladder outflow obstruction. Evidence for a correlation between the severity of obstruction and the presence of instability.

Br J Urol 1988; 61:420.

12 - MUNDY A.R. :

Detrusor instability.

Br.J.Urol.1988; 62:393

13 - CARDOZO L. :

Urethral instability in normal postmenopausal patients.

In: Proceedings of the 22nd Meeting of the International Continence Society; Halifax, September, 1992: p103.

14 - SORESON S. :

Urethral pressure variations in bealthy and incontinent women.

Neurourol Urodyn 1992;6:549

15 - MCGUIRE E.J. :

Bladder instability and stress incontinence.

Neurourol. Urodynam, 1988; 7:563.

16 - FARRAH W.K. :

An objective assessment of the unstable bladder of psychosomatic origin.

Br J Urol 1978; 50:246.

17 - FREWEN W.K. :

The significance of the psychosomatic factor in urge incontinence.

Br J Urol 1984; 56:313.

18 - JENSEN D. Jr. :

Pharmacological studies of the uninhibited neurogenic bladder.

Acta Neurol Scand 1981, 64:175. 
19 - BROWN J.H. :

Atrophine, scopolamine and related antimuscarinic drugs.

In Gilman AG, Rall TW, Nies AS, Taylor P (eds): Goodman and Gilman's The pharmacological basis of therapeutics, ed8, New York, 1990, Pergamon Press.

20 - EKSTRA?M B., ANDERSONN K.-E., MATTIASON A. :

Urodynamic effects of intravesical instillation of atropine and phentolamine in patients with detrusor byperactivity.

J Urol 1993;149:155.

21 - WEIN A.J. :

Drug treatment of voiding dysfunction.

AUA Update Series, vol7, nos.14,15. Houston 1988, American Urological Association; 106.

22 - NADZEBAKER H., JIL G. :

Control of detrusor byperreflexia by the intravesical instillation of oxybutynin bydrochloride.

Paraplegia 1991; 19:84.

23 - LEVIN R.M., STASKIN D., WEIN A.J. :

The muscarinic cholinergic binding kinetics of the buman urinary bladder.

Neurourol Urodyn 1982; 1:221.

24 - MOISEY C., STEPHENSON T., BRENDLER C. :

The urodynamic and subjective results of treatment of detrusor instability with oxybutynin chloride. Br J Urol 1980; 52:472.

25 - HEHIR M., FITZPATRIK J.M. :

Oxybutynin and the prevention of urinary incontinence in spina bifida.

Eur Urol 1985; 11:254.

26 - GAJEWSKY J.B., AWARD J.A. :

Oxybutynin versus propanthelina in patients with multiple sclerosis and detrusor byperreflexia.

J Urol 1986; 135:966.

27 - KHOLER R., MORALES P. :

Cystometric evaluation of flavoxate bydrochloridein normal and neurogenic bladders.

J Urol 1968; 100:79.

28 - JONAS U., PETRI E., KISSAL J. :

The effect of flavoxate on hyperactive detrusor muscle.

Eur Urol 1979; 5:106.

29 - BRIGGS R.S., CASTLEDEN C.M., ASHER M.J. :

The effect of flavoxate on uninbibited detrusor contractions and urinary incontinence in the elderly. J Urol 1980; 123:656. 
30 - PETERS D. :

Multicenter Study Group: Terodiline in the treatment of urinary frequency and motor urge incontinence. A controlled multicenter trial.

Scand J Urol Nephrol 1984; 87s:21.

31 - TAPP A., FAll M., NORGAARD J., MASSEY A., CHOA R., CARR T., KORHONEN M., ABRAMS P. :

Terodiline: a dose titrated, multicenter study of the treatment of idiopathic detrusor instability in women.

J Urol 1989; 142(4):1027.

32 - OUSLANDER G.C. and TERODILINE IN THE ELDERLY AMERICAN MULTICENTER STUDY GROUP :

Effects of terodiline on urinary incontinence among older non-institutionalized women.

J Am Geriatr soc 1993; 41(9):915.

33 - LINDHOLM P., LOSE G. :

Terbutaline (Bricanyl) in the treatment of female urge incontinence.

Urol Int 1986; 41:158.

34 - CASTLEDEN C., GEORGE C., REDWICK A. :

Imipramine: A possible alternative to current therapy for urinary incontinence in the elderly.

J Urol 1981; 125:218.

35 - LOSE G., JORGENSEN L., THUNEDBORG P. :

Doxepin in the treatment of female detrusor overactivity: a randomized doubleblind crossover study.

J Urol 1989;142:1024.

36 - WEIN A.J. :

Nonsurgical management of bladder dysfunction.

In Webster GD, Kirby R, Goldwasser B, King LR (eds): Reconstructive Urology. Boston, Blackwell Scientific, 1993, 403.

37 - WAGG A., BAYLliS M., INGHAM N.J., ARNOLD K., MALONE-LEE J. :

Urodynamic variables cannot be used to classify the severity of detrusor

instability.

Br J Urol 1998; 82(4): 499.

38 - ERICKSON B.C., BERGMAN S., EIK-NES S.H. :

Maximal electrostimulation of the pelvic floor in female idiopathic detrusor instability and urge incontinence.

Neurourol Urodyn 8:219, 1989

39 - CARDOZO L.D., ABRAMS P.D., STANTON S.L., FINELLY R.C.L. :

Idiopathic bladder instability treated by biofeedback.

Br J Urol 1978;50:521. 
40 - FREWEN W.K. :

Role of bladder training in the treatment of the unstable bladder in the female. Urol Clin North Am 1979; 6:273.

41 - DI BENEDETTO P., DI SILVESTRE A., ZAMPA A. :

Il trattamento fisioriabilitativo dell'incontinenza urinaria femminile.

Eur Med Phys 1987, 23:193-209.

42 - WEIN A.J. :

Drug treatment of voiding dysfunction.

AUA Update Series, vol.7, nos.14,15. Huston, American Urological Association, 1998, 106-109.

43 - COOLSAET B.L.R.A., VAN DUYL W.A., VAN-OSBOSSAGH P., DE BAKKER H.V. : New conceps in relation to urge and detrusor activity.

Neurourol Urodyn 1993; 12:463.

44 - SHAH P.F.R. :

The assessment of patients with a view to urodynamics.

In Mundy AR, Stephenson TP, Wein AJ (eds): Urodynamics: principles, practice and application 2nd ed. Churchill Livingstone, 1994, New York; 19:299.

45 - WEIN A.J., ENGLISH W.E., WHITMORE K.E. :

Office urodynamics.

Urol Clin North Am 1988; 15:609.

46 - AWARD S.A., GAJEWSKI J.B. :

Urge Incontinence.

In: O’Donnel PD (ed) Urinary Incontinence. 1997, Mosby-Year Brook; St.Louis, Missouri: 197-202.

47 - BLAIVAS J., CHANCELLOR M. :

Atlas of Urodynamics. 1996 Williams \& Wilkins, Baltimore77-87.

48 - ANDERSON R.B., SHEPHERT A.M., FENELEY R.C.L. :

Microtransducer urethral profile methodology: variation caused by transducer orientation.

J Urol 130:727, 1985.

49 - International Continence First report on the standardization of terminology of lower urinary tract function.

Br J Urol 48:39, 1979.

50 - BURNS A.P. :

Biofeedbach Therapy.

In O’Donnell P (ed): Urinary Incontinence. Mosby, 1997, St.Louis; 38:273.

51 - GALANTE T., GATTINONI F., DI BENEDETTO P. :

Il Biofeedbach.

In Di Benedetto P (ed): Riabilitazione uro-ginecologica. 1995 Torino, Minerva Medica: 115-123. 
52 - McGUIRE E.J., SAVASTO J.A. :

Stress incontinence and detrusor instability/urge incontinence.

Neurourol Urodyn,1985; 4:313.

53 - RESNICK N.M., YALLA S.V. :

Valutazione e trattamento dell'incontinenza urinaria.

In Walsh PC, RetikAB, Stamey TA, Vaughan EDJr. (eds):Urologia di Campbell 1993, 2TH It. Ed., 6ED Am.Ed. Roma, Verduci; 14:649.

54 - FALL M., LINDSTOM S.

Electrical stimulation: a physiological approach to the treatment of urinary incontinence.

Urol Clin North Am 1991, 18(2): 393-402.

55 - PLEVNIK S., JANEZ J., VODUSEK D.B. :

Electrical stimulation.

In Krane RJ, Siroky MB (eds.) Clinical neuro-urology,Boston 1991, Little, Brown.

56 - KJOLSETH D., MADSEN B., KNUDSEN L.M., NORGAARD J.P., DJURHUUS J.C. : Biofeedbach treatment of children and adults with idiopathic detrusor instability.

Scand J Urol Nephrol 1994; 28(3):243.

57 - AWARD S.A., GAJEWSKI J.B. :

Urge incontinence.

In O’Donnel P.(ed): Urinary Incontinence. 1997, Mosby, St.Louis; 26:197. 